\title{
Rearview
}

\section{Reliance Jio forces the Indian mobile market to restructure}

\section{A regular column on the information industries}

\author{
Peter Curwen
}

There is a saying in London that your expected bus will often fail to turn up on time only for two or more to turn up together. So it is with mergers and takeovers involving mobile operators in India. After a decade during which many plans to bring together more than ten operators failed to come to fruition a process described in detail in Curwen and Whalley (2017) - the market structure has been turned on its head within the space of one year. The trigger was the attempt in 2016 by new entrant Reliance Jio to lock up the long-term evolution (LTE, more commonly known as 4G) market, in its infancy at the time, by in effect providing a free service.

A list of mobile operators in existence at the commencement of 2017 can be found in Table I. At the end of January 2017, Telenor announced that it was in discussions - which did not imply that a previously mooted sale to Bharti Airtel was off the table - with RCom and Aircel with a view to a three-way merger. These discussions were, however, placed in temporary abeyance pending the Supreme Court decision to impose a temporary halt on the sale or transfer of Aircel's spectrum holdings.
On 23 February, Bharti Airtel announced that it had agreed to take over Telenor's spectrum, licences, infrastructure and operations - as ever, this was confusingly referred to as a merger when it could more realistically be deemed to be a takeover - subject to regulatory approvals which were expected to take until the latter part of 2017. In May, the requisite authorisations were forthcoming from the Securities and Exchange Board (SEB), the Bombay Stock Exchange and the National Stock Exchange of India, but the number of agencies involved in matters of restructuring in India also includes those with responsibility for matters to do with competition and foreign investment (see below) which is why it is such a long-winded process.

At the same time, Tata DoCoMo revealed that it had initiated discussions with a view to joining the proposed Aircel/RCom/SSTL merger. However, Tata DoCoMo's debt of $\$ 4.46 \mathrm{bn}$ was expected to prove something of an impediment in addition to the need to unwind NTT DoCoMo's stake in Tata DoCoMo. It was also noted that the Tata Group board had previously resolved to shut down its telecom business on a gradual basis; so, it
Peter Curwen is Professor at Newcastle Business School, Northumbria University, Newcastle upon Tyne, UK.

Received 26 July 2017

Revised 26 July 2017

Accepted 11 October 2017 
Table I State of mobile market at end-2016 ${ }^{a}$

Subscribers 30

December $2016^{b}$
Market share \% 30

December 2016
Comments

\begin{tabular}{|c|c|c|}
\hline Bharti Airtel & $265,850.000$ & 23.6 \\
\hline Vodafone & $204,690,000$ & 18.1 \\
\hline Idea Cellular & $190,520,000$ & 16 \\
\hline BSNL & $96,809,000$ & \\
\hline Aircel & $91,287,000$ & \\
\hline RCom & $86,779,000$ & \\
\hline Reliance Jioc,d & $72,300,000$ & \\
\hline Telenor & $54,096,000$ & \\
\hline Tata DoCoMo & $52,969,000$ & \\
\hline Sistema Shyam & $5,635,000$ & \\
\hline MTNL & $3,381,000$ & \\
\hline Quadrant Televentures & $3,380,000$ & \\
\hline
\end{tabular}

Take-over bid for Telenor pending approval Merger with Idea Cellular pending approval Merger with Vodafone pending approval Potential merger with MTNL Merger with RCom pending approval Merger with Aircel pending approval 100 million subscribers by February 2017 Under offer from Bharti Airtel Tata buying DoCoMo stake Set to become a subsidiary of RCom Potential merger with BSNL Part of Videocon Group. Closed down

Notes: ${ }^{\text {TThere }}$ were $1,127,00,000$ subscribers in total at the end of 2016 of whom $988,000,000$ (87.7 per cent) were active. Private operators accounted for 91.1 per cent of the total market; ' $I n$ March, the DoT ordered all operators to re-verify their subscribers by February 2018 using the Aadhaar identification system already used by Reliance Jio; 'Although Reliance Jio had taken a 6.4 per cent market share from other operators, this was not especially from the top three whose combined market share fell only from 61 per cent

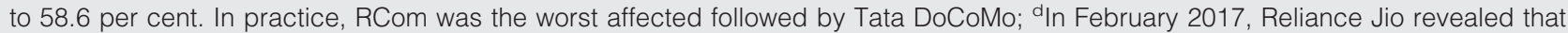
its network was carrying one exabyte (one billion gigabytes) of data a month and two billion minutes of voice and video traffic a day, making it the world's busiest network in terms of data carried-twice as much as all of China and nearly as much as the USA Source: Telecom Regulatory Authority of India (2017) Highlights of Telecom subscription data as on 31st December 2016. Press Release No.12/2017. New Delhi: TRAI, 17 February

would be unlikely to want to take a stake in the merged entity.

As for Bharti Airtel, it published data indicating a significant drop in profitability due to competition pressures. It noted in particular that it was terminating huge numbers of calls originating from the Reliance Jio network at a price below the cost of provision of that facility. The financial damage inflicted by Reliance Jio was also noted in the final quarter of 2016 results posted by Idea Cellular and RCom. Idea recorded a net loss of $\$ 57.6 \mathrm{~m}$ and noted both that its wireless revenues were trending downwards for the first time and that it had registered its first-ever net loss of data users. As for RCom, it recorded a net loss of both data subscribers and overall subscribers.

In February, it was revealed that Reliance Jio had acquired 72.2 million subscribers by end-2016 and that these had broken the 100-million barrier by 15 February. This was attributed in part to the new Aadhaar identification system which included biometric data and enabled Jio instantly to verify a subscriber's identity. Reliance Jio also revealed its price plans taking effect from 1 April. All those who were customers by that date would be eligible for a new "Jio Prime Membership Programme" that would involve a one-off enrolment fee of INR99 (\$1.55) plus INR303 (\$4.75) a month thereafter for unlimited usage - but throttled back if excessive. A new "Everyday More Value Offer" would also be made available that would allow customers to pick the best-selling tariff provided by a rival operator and obtain the same tariff from Reliance Jio with 20 per cent more data provided.

These tariffs indicated only too clearly that Reliance Jio had no intention of slackening significantly the pressure of competition but at what cost to itself? Evidently, one that could be borne by its parent since, in early April, Reliance reported that it had already acquired 72 million subscribers to its Prime Membership. It duly extended the above offer to 15 April and introduced "Jio Summer Surprise" for its Prime members. Provided that they made their first paid recharge by 15 April using a plan costing at least INR303, they would receive free services for three months and only need to begin payments in July. Within days, the telecoms regulator, the TRAI, requested that Jio withdraw this offer and Jio agreed subject to retaining eligibility for all those already signed up to the plan.

Reliance Jio responded with the introduction of "Dahn Dhana Dahn" plans that were substantively the same as the "Summer Surprise" plans and also made them available to non-Prime customers for a small additional cost. However, Bharti Airtel and Vodafone protested vociferously and Reliance Jio fully withdrew the offers but promptly replaced them with "All Unlimited" plans, exclusive to its Jio Prime members, that provided unlimited calls, SMS and up to 1 or 2 GB of data - depending on the price set at roughly $\$ 5$ and 8 , respectively - at $4 \mathrm{G}$ speeds for three months 
commencing with the first recharge. Reliance Jio also went on the attack against its rivals by claiming that Bharti Airtel, Idea and Vodafone were engaging in unfair and deceptive practices to retain customers - specifically via the offering of discounts and bonuses to influence customers interested in porting their numbers to Reliance Jio. It also alleged that rivals' call centres were providing false information regarding its network coverage and service quality.

In April, Reliance Jio revealed that it had acquired 108.9 million customers by the end of March but that its revenue for the financial year had fallen heavily while costs had surged leading to a net loss for the year of $\$ 485 \mathrm{~m}$. However, it considered itself to be successful because 72 million customers had signed up for Jio Prime.

It was not only the operators but also (inevitably for India) the regulatory bodies who were feuding. For example, in March, open warfare broke out between the TRAI and the Department of Telecommunications (DoT). In response to the accusation that it had been dilatory in dealing with the alleged rule-breaking by Reliance Jio, the TRAI responded by stating that it had on several occasions notified the DoT recommending such matters as reductions in licence fees and the need to relax the payment schedule for licence fees. In particular, it was claimed that every attempt to reduce the burden on heavily indebted operators had been spurned because it meant a reduction in tax revenues. For its part, the Telecoms Disputes Settlement and Appellate Tribunal re-examined whether Reliance Jio had broken its rules.

Rumours circulated yet again to the effect that state-owned BSNL and MTNL would seek to merge although the latter's debts of over \$3bn together with its ongoing annual losses were hardly likely to appeal to BSNL which was itself finally showing signs of moving towards break-even. Indeed, BSNL promptly announced that it intended to roll out 4G by March 2018 followed by a rapid launch.

In mid-March, the SEB and the Competition Commission cleared the merger between RCom and Aircel which had previously been agreed by the Bombay and National Stock Exchanges. However, further permissions were still pending.

Shortly thereafter, the much-anticipated announcement of an agreed merger between Vodafone and Idea Cellular, subject to regulatory approval, provided yet further evidence that the disruptive behaviour of Reliance Jio would shake up the market structure in a major way. New shares in Idea would be issued to Vodafone which would end up with a 45.1 per cent stake after selling on 4.9 per cent to the Aditya Birla Group, which would itself end up with a 26 per cent stake (with the right to purchase a further 9.5 per cent from Vodafone at a later date to equalise their respective stakes). The remainder would be held by the other shareholders in Aditya Birla. Not only would Vodafone/ldea become potentially the largest operator in terms of subscriber market share but also it would end up with more than 40 per cent of market revenue - at least until Reliance Jio began to charge its customers. The new operator - as yet unnamed - would control 1,850 MHz of spectrum, mostly acquired via auctions although some would have to be returned to comply with spectrum caps.

It was of interest that excluding the stakes in Indus Towers - Vodafone India would not be including its 45 per cent stake in the deal - the operators were valued at \$12.4bn and \$10.8bn for Vodafone and Idea, respectively, whereas the net debt to be contributed was estimated at $\$ 8.2 \mathrm{bn}$ and $\$ 7.9 \mathrm{bn}$, respectively. This indicated that the two operators would not be worth all that much if they repaid their debts. However, these would be reduced via the sale of all stand-alone towers and Aditya Birla's 11.1 per cent stake in Indus Towers.

Later in March it was announced that RCom had been authorised by the SEB to merge with SSTL, with other permissions still awaited. The plan remained for SSTL to be folded into RCom with SSTL taking a 10 per cent stake in the merged entity.

For its part, Bharti Airtel remained active, on this occasion completing a deal to acquire Tikona Digital Networks' $20 \mathrm{MHz}$ of $2.3 \mathrm{GHz}$ spectrum currently being used for TD-LTE in a number of circles. As a result, Bharti ended up with $30 \mathrm{MHz}$ in the band in 13 circles. Tikona would continue to provide a service using its $2.6 \mathrm{GHz}$ spectrum.

In early May, the saga involving ownership of Tata Teleservices finally approached a conclusion when the High Court of Delhi moved to enforce the arbitration award from the London Court of International Arbitration laid down in June 2016 and involving the payment of $\$ 1.18$ bn by Tata Sons (previously deposited with the High Court) in return for the DoCoMo shareholding. In May, the Competition Commission of India was asked to authorize the payment. Subsequently, in early July, it was claimed that a merger was being discussed that would involve Bharti Airtel, Tata Teleservices, Tata Sky and Tata Communications. Bharti would thereby acquire spectrum in the 800 and 1,800 $\mathrm{MHz}$ bands and an expanded fibre-optic cable footprint. However, one obvious problem would be the billions of dollars of 
debt taken on by Tata Group companies and another the need for minority shareholders in Tata Group companies, including the Indian government, to agree the deal.

Were this and the other mergers discussed above to take place, only 5 operators would remain from the 11 shown in Table I.

Table I can be compared to the situation in the broadband market where there were 236.1 million subscribers at end-2016 - an unusually large proportion of the market in India remains 2G only. Reliance Jio led the market with 72.3 million (30.6 per cent) because it was exclusively offering $4 \mathrm{G}$ connectivity, whereas Bharti lagged well behind with 43.6 million (18.5 per cent) followed by Vodafone with 35.0 million (14.8 per cent), Idea Cellular with 27.0 million (11.4 per cent) and BSNL with 20.4 million (8.6 per cent). These five operators accordingly accounted for 83.9 per cent of the total market.

Just how much pain Reliance Jio was inflicting on its rivals became clear in May when Bharti Airtel reported its results for 2017Q1. Total revenue in India had fallen by 7.1 per cent compared to a year earlier. However, this was an improvement upon Idea Cellular which reported a 14.3 per cent decline in total revenue during the same period. Although the total number of subscriptions was on the rise, the number of data subscriptions had fallen significantly and as a result Idea declared its first annual net loss for the financial year ending 31 March since 2007. For its part, Tata Teleservices stated that its total revenue had decreased by 9 per cent, year-on-year. As for RCom, it reported a 10.8 per cent year-on-year drop in consolidated total revenue reflecting a massive reduction in overall subscribers from 103.6 million to 84.7 million and in data subscribers from 38.9 million to 28.3 million.

Subsequently, RCom's lenders gave it a period of grace to reduce its debts in part via the completion of its proposed merger with Aircel, leading to the creation of a new entity to be known as "Aircom". In July, RCom asked the government for permission to return part of its spectrum - comprising four blocks of $0.6 \mathrm{MHz}$ paired in the $1,800 \mathrm{MHz}$ band acquired in 2014 and 2015 with a view to avoiding outstanding payments.

For its part, Tata Teleservices approached a consortium led by the State Bank of India with a view to restructuring its $\$ 5 \mathrm{bn}$ debt, whereas MTNL asked the government to extend its licences in Delhi and Mumbai by two years at no cost to itself on the grounds that the licence had been left dormant during the first four years post-issue. It pointed out that the licence had not been handed over until two and a half years of the licence period had elapsed.

However, the economic pain was also shared by the government which was forced to admit in June that "severe financial stress" among operators would result in an expected 37 per cent reduction in the revenue forthcoming from the telecoms sector in the year ending 31 March 2018, in part because it would not be possible to hold any further auctions.

In conclusion, it is notable that no mobile market has ever been subjected to the kinds of forces that are driving restructuring in India. The restructuring process is taking time, but this reflects not only the time it takes for operators to agree terms with one another but, particularly in India, the large number of regulatory agencies that need to be satisfied. Nevertheless, in the end India may only be left with four or five nationwide operators.

\section{Reference}

Curwen, P. and Whalley, J. (2017), "A tale of many auctions: mobile communications in India struggle to overcome a dysfunctional structure", Digital Policy, Regulation and Governance, Vol. 19 No. 3, pp. 225-250.

\section{Corresponding author}

Peter Curwen can be contacted at: pjcurwen@hotmail.com 